\title{
Contribution of bioinformatics predictions and functional splicing assays to the interpretation of unclassified variants of the BRCA genes
}

\author{
Jean Christophe Théry ${ }^{1,6}$, Sophie Krieger ${ }^{2,6}$, Pascaline Gaildrat ${ }^{1}$, Françoise Révillion ${ }^{3}$, Marie-Pierre Buisine ${ }^{1}$, \\ Audrey Killian ${ }^{1}$, Christiane Duponchel ${ }^{1}$, Antoine Rousselin ${ }^{2}$, Dominique Vaur ${ }^{2}$, Jean-Philippe Peyrat ${ }^{3}$, \\ Pascaline Berthet $^{4}$, Thierry Frébourg ${ }^{1,5}$, Alexandra Martins ${ }^{1}$, Agnès Hardouin ${ }^{2}$ and Mario Tosi ${ }^{\star, 1}$
}

\begin{abstract}
A large fraction of sequence variants of unknown significance (VUS) of the breast and ovarian cancer susceptibility genes $B R C A 1$ and BRCA2 may induce splicing defects. We analyzed 53 VUSs of BRCA1 or BRCA2, detected in consecutive molecular screenings, by using five splicing prediction programs, and we classified them into two groups according to the strength of the predictions. In parallel, we tested them by using functional splicing assays. A total of 10 VUSs were predicted by two or more programs to induce a significant reduction of splice site strength or activation of cryptic splice sites or generation of new splice sites. Minigene-based splicing assays confirmed four of these predictions. Five additional VUSs, all at internal exon positions, were not predicted to induce alterations of splice sites, but revealed variable levels of exon skipping, most likely induced by the modification of exonic splicing regulatory elements. We provide new data in favor of the pathogenic nature of the variants $B R C A 1 \mathrm{c} .212+3 A>G$ and $B R C A 1$ c.5194 $-12 \mathrm{G}>\mathrm{A}$, which induced aberrant out-of-frame mRNA forms. Moreover, the novel variant BRCA2 c.7977-7C $>\mathrm{G}$ induced in frame inclusion of $6 \mathrm{nt}$ from the $3^{\prime}$ end of intron 17. The novel variants $B R C A 2$ c.520C $>T$ and BRCA2 c.7992T $>A$ induced incomplete skipping of exons 7 and 18, respectively. This work highlights the contribution of splicing minigene assays to the assessment of pathogenicity, not only when patient RNA is not available, but also as a tool to improve the accuracy of bioinformatics predictions.
\end{abstract}

European Journal of Human Genetics (2011) 19, 1052-1058; doi:10.1038/ejhg.2011.100; published online 15 June 2011

Keywords: variants of unknown significance; splicing defects; splicing reporter minigene; breast and ovarian cancer; BRCA1 and BRCA2

\section{INTRODUCTION}

The interpretation of variants of unknown significance (VUS) found in the molecular screenings of the breast and ovarian cancer susceptibility genes, $B R C A 1$ and $B R C A 2$, is essential for genetic counseling of patients and their families and for the implementation of new therapies targeted to carriers of BRCA mutations, such as those based on poly-(ADP-ribose) polymerase inhibitors. ${ }^{1}$ The number of these variants already exceeds that of the reported pathogenic mutations, and is expected to increase rapidly with the use of new high throughput sequencing technologies that are based on massive parallel sequencing. ${ }^{2}$

It is now widely accepted that RNA analyses should be used to improve the assessment of pathogenicity of sequence variation, because a large fraction of sequence variants, both intronic and exonic, may induce splicing defects. However, in many cases, patient RNA is either not available or it has been obtained in ways that do not ensure its stability. Moreover, it is sometimes difficult to detect the mRNA affected by a truncating mutation because of the activation of the nonsense-mediated mRNA decay pathway. ${ }^{3}$

Functional assays of the effect of VUS on RNA splicing, using patient genomic DNA and a splicing reporter hybrid minigene, focus on the gene region carrying the variation and compare the wildtype and the variant sequence under identical conditions, thus providing direct proof of the involvement of the sequence change in the splicing alteration. ${ }^{4,5}$ These assays are also very useful to clarify ambiguities of reverse transcriptase (RT)-PCR data obtained from patient RNA.,7

We have previously compared the results of splicing reporter minigene assays with those of patient blood RNA analyses, on large numbers of VUS of the mismatch repair genes ${ }^{6}$ as well as of the BRCA genes. ${ }^{7}$ Although these assays test variants in an artificial exon context, we showed that they detect rather accurately VUSs that induce splicing alterations.

Considering the very large numbers of VUSs of the BRCA1 or $B R C A 2$ gene that could potentially affect RNA splicing, it is essential to define strategies for the stratification of functional assays. Several recent studies indicate that, for routine applications in molecular diagnostic laboratories, bioinformatics predictions are useful, at this time, only for variants that affect exon-intron junctions or generate new splice sites, or induce the use of cryptic sites by decreasing the strength of natural splice sites. ${ }^{6-10}$

${ }^{1}$ Inserm U614, IFRMP, Faculty of Medicine and Department of Genetics, University Hospital, Institute for Biomedical Research and Innovation, Rouen, France; ${ }^{2}$ Laboratoire de Biologie Clinique et Oncologique, Centre François Baclesse, Caen, France; ${ }^{3}$ Laboratoire d'Oncologie Moléculaire Humaine Centre Oscar Lambret, Lille, France; ${ }^{4}$ Consultation d'Oncogénétique, Centre François Baclesse, Caen, France; ${ }^{5}$ Clinical Genetics Unit, Department of Genetics, CHU de Rouen, Rouen, France

*Correspondence: Professor M Tosi, Inserm U614, IFRMP, Faculty of Medicine and Department of Genetics, University Hospital, Institute for Biomedical Research and Innovation, French Northwest Canceropole, 22 Boulevard Gambetta, Rouen 76183, France. Tel: +33 235148311 ; Fax: +33 23 514 8237 ; E-mail: mario.tosi@univ-rouen.fr 6These authors contributed equally to this work

Received 8 February 2011; revised 27 April 2011; accepted 29 April 2011; published online 15 June 2011 
The main purpose of this study was to evaluate, in the molecular diagnostic context, the performance of bioinformatics predictions for the selection of variants that potentially induce splicing alterations. To this end, we studied 53 VUSs of BRCA1 or BRCA2 (30 in exons and 23 in introns) found in consecutive molecular screenings in the laboratories of the French Northwest Canceropole (Caen, Lille and Rouen) in the years 2008 and 2009. We applied to these VUSs an extensive bioinformatics analysis using most of the available software that predict changes of splice site strength or position. We have not attempted in this work to predict alterations of splicing regulatory elements. In parallel, we tested all 53 VUSs using a minigene-based splicing assay and, in a majority of cases, also by RT-PCR analyses on patient blood RNA.

\section{PATIENTS AND METHODS}

\section{Patients}

The 53 BRCA1 or BRCA2 variants tested were detected in index cases selected from families undergoing genetic counseling in the French North West breast cancer genetics network. The criteria for diagnostic mutation screening of $B R C A$ genes were according to the current French recommendations. All families were tested for the presence of BRCA1 or BRCA2 point mutations or small deletions/insertions using denaturing high-performance liquid chromatography or high-resolution melting) followed by sequencing. Screening for large genomic rearrangements of $B R C A 1$ was performed for all probands with a combination of the multiplex ligation-dependent probe amplification method and the quantitative multiplex PCR of short fluorescent fragment method. ${ }^{11,12}$ These analyses failed to reveal obviously pathogenic mutations. All patients and controls gave signed informed consent.

\section{Nomenclature}

The DNA mutation numbering is based on the CDNA sequence for BRCA1 (GenBank NM_007294) and BRCA2 (GenBank NM_000059). The nomenclature system for the description of changes in DNA, RNA and protein follows the recommendations of the Human Genome Variation Society, with numbering starting at the first position of the translation initiation codon.

\section{Blood samples, nucleic acid extraction and RT-PCR analysis on patient blood RNA}

Patient DNA was isolated from peripheral blood samples collected in EDTA tubes using either a manual (QIAamp DNA mini kit) or an automated (EZ1 DNA Blood kit on BioRobot EZ1 workstation) procedure (both from Qiagen, Hilden, Germany). For RNA analysis, whole blood was collected from patients and voluntary control subjects (PAXgene Blood RNA tubes; Qiagen). RNA extraction and RT-PCR were performed as previously described. ${ }^{7,13}$

\section{Splicing predictions}

Five different splice site prediction algorithms were used: Splice Site Finder (SSF-like, see http://www.interactive-biosoftware.com), Gene Splicer (GS, http://www.tigr.org/tdb/GeneSplicer/gene_spl.html), splice site prediction by Neural Network (NNS, http://www.fruitfly.org/seq_tools/splice.html), MaxEntScan (MES, http://genes.mit.edu/burgelab/maxent/Xmaxentscan_scoreseq.html) and Human Splicing Finder (HSF, http://www.umd.be/HSF/). SSF, MES, GS and NNS were interrogated simultaneously using the integrated software Alamut V.1.5 (Interactive Biosofware; http://www.interactive-biosoftware.com). Default thresholds were used for all the analyses.

\section{Databases}

The following databases were consulted: Breast Cancer Information Core: http://research.nhgri.nih.gov/bic/; Leiden Open Variation Database v.2.0; http://chromium.liacs.nl/LOVD2/cancer/home.php.

Ex vivo splicing assay using a reporter minigene

$B R C A 1$ or $B R C A 2$ exons relevant to this study were amplified by PCR from genomic patient DNA, including $\sim 150 \mathrm{bp}$ of $5^{\prime}$ and $3^{\prime}$ flanking intronic sequences, using forward and reverse primers carrying $5^{\prime}$ tails that contained restriction sites for BamHI and MluI, respectively. Primer sequences are available on request. When the region to be amplified contained one of these restriction sites, the primer tails included the restriction sites BglII or AscI, which are compatible with the BamHI and MluI sites, respectively, present in the splicing reporter minigene pCAS. Detailed descriptions of this splicing reporter minigene have been published. ${ }^{4,6}$

Minigenes carrying the wild-type and the variant genomic segment were then identified by plasmid sequencing and were transfected separately into HeLa cells. Cell transfections, recovery of RNA from transfected cells and analysis of mRNA expressed from the hybrid minigene constructs were performed as previously described. ${ }^{4,6}$ The HeLa cell line, derived from human cervical cancer cells, was used because these cells have a high transfection efficiency and because many biochemical studies on mRNA splicing are performed with HeLa nuclear extracts.

\section{RESULTS}

\section{Variants predicted to induce splice site changes}

We evaluated the effect of 53 consecutive VUSs on RNA splicing by using five bioinformatics programs (SSF, MES, GS, NNS and HSF, see Patients and methods) that predict changes of splice site strength or generation of new splice site, or activation of cryptic splice sites. The distribution of these VUSs was as follows: 26 in BRCA1 (14 in introns, 12 in exons, including 4 silent substitutions) and 27 in BRCA2 (9 in introns, 18 in exons, including 8 silent substitutions) as shown in Supplementary Table S1. Mutations of the conserved GT and AG positions at the $5^{\prime}$ and the $3^{\prime}$ boundary of introns, respectively, were not considered. Moreover, VUS affecting exon 11 of $B R C A 1$ or exon 11 of $B R C A 2$ were excluded, because the large exon size would require special minigene constructs for functional splicing analyses.

We defined as belonging to the group of strong predictions (here denoted type 1 predictions), the VUS for which (i) decrease by at least $10 \%$ of the score of natural splice sites was predicted by at least two algorithms, or (ii) the generation of a novel splice site with a score similar to or higher than the natural one was predicted by at least two algorithms, or (iii) the natural splice site was predicted by at least two algorithms to have reduced strength and a strong cryptic site was predicted to be present in the surrounding exonic or intronic sequence. By default, we classified all other VUSs in a group denoted type 2 predictions. To evaluate the accuracy of type 1 predictions, we tested all 53 VUSs by using the previously described pCAS minigene assay ${ }^{4,6,7}$ and by performing RT-PCR analyses on patient RNA, whenever available, that is, in 30 cases $(56 \%)$. These variants and their effects in the minigene assay and in the patient RNA are shown in Supplementary Table S1.

The group of type 1 bioinformatics predictions comprised 10 VUSs (listed in Tables 1 and 2). These predictions were confirmed by minigene-based analyses in four cases (Table 1). The six type 1 predictions that were not confirmed are listed in Table 2.

BRCA1 c. $212+3 \mathrm{~A}>\mathrm{G}$ was predicted to reduce the score of the natural donor splice site (DSS) and to activate an exonic cryptic DSS (Supplementary Table S2). Indeed, this variant induced, in the functional splicing assay, the production of an altered mRNA form, deleting $22 \mathrm{nt}$ from the $3^{\prime}$ end of exon 5 (Figure 1a). We confirmed the presence of this defect in patient blood RNA (Table 1).

BRCA1 c.5194-12G $>$ A was predicted to induce the creation of a strong intronic acceptor splice site (ASS) while reducing the strength of the natural ASS (Supplementary Table S2). This variant induced, in the functional splicing assay, the production of an mRNA species including $10 \mathrm{nt}$ from the $3^{\prime}$ end of intron 19 (Figure 1b). RNA was not available from patients carrying this sequence change. 
Table 1 Description of the four BRCA variants associated with type 1 prediction that induce splicing alterations in functional minigene assay

Detection of splicing defects

\begin{tabular}{|c|c|c|c|c|}
\hline $\begin{array}{l}\text { Gene, } \\
\text { location }\end{array}$ & $\begin{array}{l}\text { Nucleotide variant } \\
\text { (HGVS) codon }\end{array}$ & Minigene assay & $\begin{array}{l}\text { Analysis of } \\
\text { patient RNA }\end{array}$ & $\begin{array}{l}\text { Previous reports concerning pathogenicity } \\
\text { (BIC/LOVD/literature) and our family data }\end{array}$ \\
\hline $\begin{array}{l}\text { BRCA1, } \\
\text { intron } 5\end{array}$ & c. $212+3 A>G$ & $\begin{array}{l}\text { Natural DSS not used and exonic cryptic DSS activated } \\
\text { Consequences: deletion of } 22 \mathrm{nt} \text { from } 3^{\prime} \text { of exon } 5 \text {, } \\
\text { induction of a frameshift }\end{array}$ & $\begin{array}{l}\text { Same as in } \\
\text { minigene assay }\end{array}$ & $\begin{array}{l}\text { BIC } 13 \text { times } \\
\text { Splicing defect (patient LCL RNA) } \\
\text { No splicing defect (patient LCL RNA) } \\
\text { Predicted deleterious (multifactorial LR model) }\end{array}$ \\
\hline $\begin{array}{l}\text { BRCA1, } \\
\text { intron } 19\end{array}$ & c. $5194-12 G>A$ & $\begin{array}{l}\text { Creation of a new intronic ASS that replaces the natural ASS } \\
\text { Consequences: insertion of } 10 \mathrm{nt} \text { from } 3^{\prime} \text { of intron } 19, \\
\text { induction of a frameshift }\end{array}$ & ND & $\begin{array}{l}\text { BIC five times } \\
\text { Predicted deleterious (multifactorial LR model) })^{15,17} \\
\text { Splicing defect (patient LCL RNA) }{ }^{17}\end{array}$ \\
\hline $\begin{array}{l}B R C A 2 \\
\text { intron } 17\end{array}$ & c. $7977-7 C>G$ & $\begin{array}{l}\text { Creation of a new intronic ASS that replaces the natural ASS } \\
\text { Consequences: an in frame insertion of } 6 \mathrm{nt} \text { from } \\
3^{\prime} \text { of intron 17. A minor species lacks exon } 18\end{array}$ & $\begin{array}{l}\text { Same as in } \\
\text { minigene assay }\end{array}$ & $\begin{array}{l}\text { Novel mutation } \\
\text { Family 1: } 2 B C \text {, first degree }\left(39^{*}, 60\right) \\
\text { Family 2: } 2 B C \text {, second degree }\left(53^{*}, 22 \text { bilateral }\right)+1 \\
\text { pancreas and prostate cancer, first degree }(66)\end{array}$ \\
\hline $\begin{array}{l}B R C A 2 \\
\text { exon } 18\end{array}$ & $\begin{array}{l}\text { c. } 8168 \text { A }>\text { G } \\
\text { p.Asp2723Gly }\end{array}$ & $\begin{array}{l}\text { Creation of a new exonic DSS, partially used } \\
\text { Consequences: a subset of transcripts contain full length exon } 18 \\
\text { carrying the variant, whereas another subset of transcripts have a } \\
\text { deletion of } 164 \mathrm{nt} \text { from } 3^{\prime} \text { of exon } 18 \text {, which induces a frameshift }\end{array}$ & ND & $\begin{array}{l}\text { BIC six times } \\
\text { Splicing defect (patient LCL RNA; }{ }^{21} \text { minigene assay) }{ }^{20} \\
\text { Reduced protein activity (HDR assay) })^{25} \\
\text { Predicted deleterious (multifactorial LR model; }{ }^{15,25} \\
\text { protein LR model) }^{22}\end{array}$ \\
\hline
\end{tabular}

Abbreviations: ASS, acceptor splice site; BC, breast cancer; DSS, donor splice site; HDR, homology-directed repair; LCL, lymphoblastoid cell line; LR, likelihood ratio; ND, not determined (patient RNA not available).

aNumber of BCs with age at diagnosis in parenthesis.

*Tested patients.

Table 2 Description of the six BRCA variants associated with type 1 prediction that do not induce splicing alterations in functional minigene assays

\begin{tabular}{|c|c|c|c|c|c|c|c|c|}
\hline \multirow[b]{2}{*}{$\begin{array}{l}\text { Gene, } \\
\text { location }\end{array}$} & \multirow{2}{*}{$\begin{array}{l}\text { Nucleotide } \\
\text { variant } \\
\text { (HGVS) } \\
\text { Codon }\end{array}$} & \multirow{2}{*}{$\begin{array}{l}\text { Analysis } \\
\text { of patient } \\
\text { RNA }\end{array}$} & \multicolumn{5}{|c|}{ Bioinformatics predictions of splice site scores ${ }^{a}$} & \multirow[b]{2}{*}{$\begin{array}{l}\text { Previous reports } \\
\text { (BIC/LOVD/literature) }\end{array}$} \\
\hline & & & $\begin{array}{l}S S F(0-100)^{b} \\
\text { Th. } \geq 60\end{array}$ & $\begin{array}{l}\text { MESC } \\
\text { Th. } \geq 0\end{array}$ & $\begin{array}{l}\text { GS }(0-15)^{b} \\
\text { Th. } \geq 0\end{array}$ & $\begin{array}{l}\text { NNS }(0-1)^{\mathrm{b}} \\
\text { Th. } \geq 0.4\end{array}$ & $\begin{array}{l}H S F(0-100)^{b} \\
\text { Th. } \geq 65\end{array}$ & \\
\hline $\begin{array}{l}B R C A 1, \\
\text { intron } 2\end{array}$ & c. $81-18 \mathrm{C}>\mathrm{A}$ & ND & $70.1=$ & $\begin{array}{c}7.0 \rightarrow 6.2 \\
(-11.6 \%)\end{array}$ & $\begin{array}{l}4.5 \rightarrow 3.9 \\
(12.4 \%)\end{array}$ & $\begin{array}{l}0.52 \rightarrow 0.43 \\
(-16.0 \%)\end{array}$ & $77.3=$ & None \\
\hline $\begin{array}{l}B R C A 1 \\
\text { intron } 2\end{array}$ & c. $81-13 \mathrm{C}>\mathrm{A}$ & No alteration & $\begin{array}{c}70.1 \rightarrow 67.4 \\
(-3.8 \%)\end{array}$ & $\begin{array}{c}7.0 \rightarrow 5.3 \\
(-25.4 \%)\end{array}$ & $\begin{array}{l}4.5 \rightarrow 2.6 \\
(-41.0 \%)\end{array}$ & $0.52 \rightarrow$ B.th. & $77.3=$ & BIC once \\
\hline $\begin{array}{l}B R C A 1 \\
\text { exon } 22\end{array}$ & $\begin{array}{l}\text { c. } 5334 \mathrm{~T}>\mathrm{C} \\
\text { p.Asp1778Asp }\end{array}$ & No alteration & $73=$ & $\begin{array}{c}8.7 \rightarrow 7.5 \\
(-13.2 \%)\end{array}$ & $\begin{array}{r}6.4 \rightarrow 5.2 \\
(-19.1 \%)\end{array}$ & $\begin{array}{l}0.67 \rightarrow 0.46 \\
(-32.5 \%)\end{array}$ & $\begin{array}{c}80.5 \rightarrow 79.6 \\
(-1.1 \%)\end{array}$ & None \\
\hline $\begin{array}{l}B R C A 2, \\
\text { intron } 2\end{array}$ & c.68-7T $>A$ & $\begin{array}{l}\text { Enhanced } \\
\text { exon } 3 \\
\text { skipping }\end{array}$ & $\begin{array}{c}87.9 \rightarrow 82.9 \\
(-5.7 \%)\end{array}$ & $\begin{array}{c}6.1 \rightarrow 4.6 \\
(-23.9 \%)\end{array}$ & $\mathrm{NI}$ & $\begin{array}{l}0.94 \rightarrow 0.68 \\
(-27.3 \%)\end{array}$ & $\begin{array}{l}80.6 \rightarrow 78.5 \\
\quad(-2.6 \%)\end{array}$ & $\begin{array}{l}\text { BIC } 4 \text { times. Enhanced } \\
\text { exon } 3 \text { skipping } \\
\text { (fibroblast patient RNA) }^{8}\end{array}$ \\
\hline $\begin{array}{l}B R C A 2 \\
\text { intron } 6\end{array}$ & c. $517-20 A>G$ & No alteration & $94.4=$ & $\begin{array}{l}10.0 \rightarrow 9.0 \\
(-10.2 \%)\end{array}$ & $\begin{array}{c}8.3 \rightarrow 6.5 \\
(-21.8 \%)\end{array}$ & $0.98=$ & $96.6=$ & None \\
\hline $\begin{array}{l}B R C A 2, \\
\text { intron } 25\end{array}$ & c. $9501+4 A>G$ & No alteration & $\begin{array}{c}91.9 \rightarrow 81.8 \\
(-11.0 \%)\end{array}$ & $\begin{array}{l}10.3 \rightarrow 7.8 \\
(-\mathbf{2 4 . 0 \%})\end{array}$ & $\begin{aligned} & 1.6 \rightarrow 0 \\
&(-100 \%)\end{aligned}$ & $\begin{array}{l}0.99 \rightarrow 0.78 \\
(-21.4 \%)\end{array}$ & $\begin{array}{c}96.3 \rightarrow 88.0 \\
(-8.6 \%)\end{array}$ & BIC twice \\
\hline
\end{tabular}

Abbreviations: B.th., below threshold; GS, Gene Splice; HSF, Human Splicing Finder; MES, MaxEntScan; ND, not determined (patient RNA not available); NI, not informative (natural splice site not predicted); NNS, Neural Networks; SSF, Splice Site Finder; Th., threshold; =, score unchanged.

a\% Change relative to wild-type sequence, in bold if $>10 \%$.

bRange.

cRange (0-16) for acceptor splice site and (0-12) for donor splice site.

BRCA2 c.7977-7C $>\mathrm{G}$ was predicted to create a strong intronic ASS while reducing the strength of the natural ASS (Supplementary Table S2). This variant induced the production of an mRNA species that included $6 \mathrm{nt}$ of the $3^{\prime}$ end of intron 17 (Figure 1c). No trace of normal exon inclusion was found by sequencing and a minor species lacking exon 18 was also observed. The inclusion of $6 \mathrm{nt}$ of intron 17 was confirmed by RT-PCR analyses of patient blood RNA (Table 1).

For BRCA2 c.8168A $>\mathrm{G}$, creation of a strong potential DSS was predicted within exon 18 . The minigene assay showed an incomplete effect, with presence of a major product containing the exon 18 sequence together with a minor product lacking the last $164 \mathrm{nt}$ of this exon (Figure 1d). Patient RNA was not available for this variant (Table 1).

As shown in Table 2, bioinformatics predictions highlighted six additional VUS with type 1 predictions, for which no effect on RNA splicing was observed using minigene assays: BRCA1 c.81-13C $>\mathrm{A}$, BRCA1 c.81-18C>A, BRCA1 c.5334T>C, BRCA2 c.68-7T>A, $B R C A 2$ c. $517-20 A>G$ and $B R C A 2$ c. $9501+4 A>G$. Absence of 

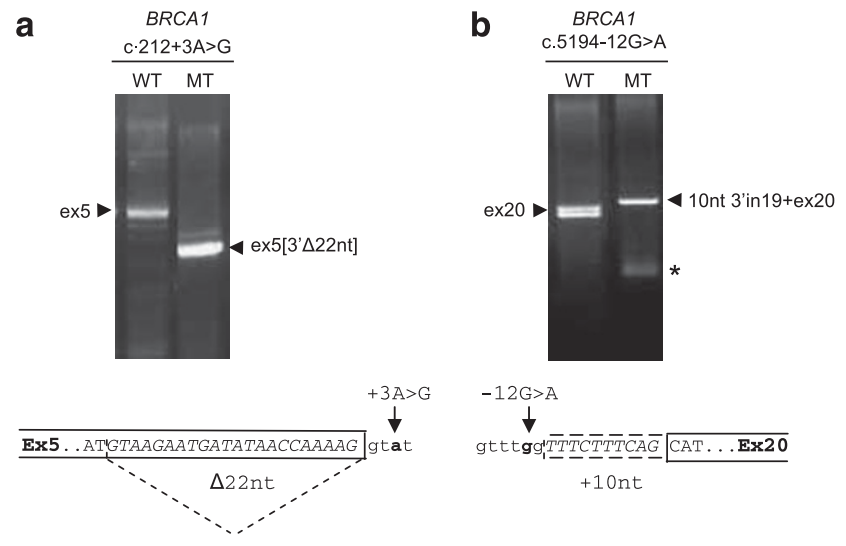

C
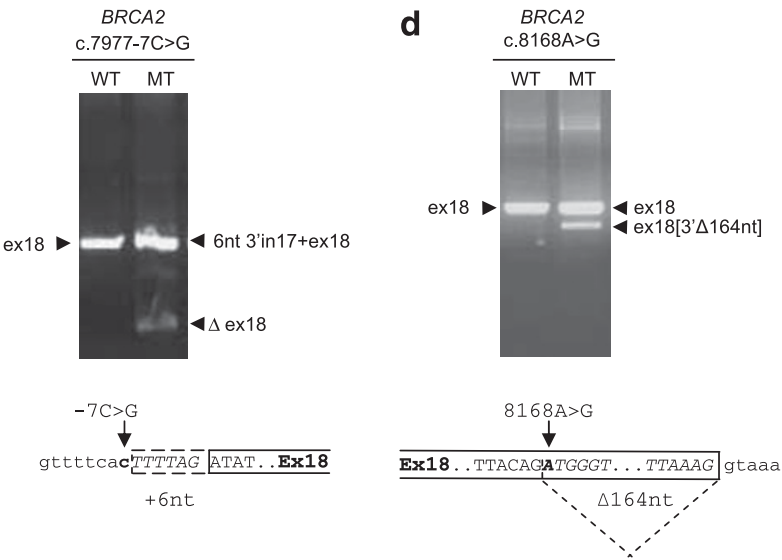

Figure 1 Variants with type 1 predictions, that induce splicing alterations in functional minigene assays. RT-PCR analyses of the spliced transcripts expressed, after parallel transfection into HeLa cells, from pCAS minigene constructs carrying the wild-type sequence (WT) or the variant (MT) listed in Table 1. In each panel, RT-PCR products obtained after transfection with the wild-type or with a variant sequences were compared. The precise nature of aberrant transcripts obtained, as deduced from systematic sequencing of all RT-PCR products, is shown at the bottom of each panel. (a) Deletion of $22 \mathrm{nt}$ (sequence in italics) of BRCA1 exon 5 (open box). (b) Inclusion of 10 nt of BRCA1 intron 19 (dashed box, sequence in italics). A star marks a weak spurious band, which is the result of primer dimerization. (c) Inclusion of $6 \mathrm{nt}$ of BRCA2 intron 17 (dashed box, sequence in italics). (d) Deletion of $164 \mathrm{nt}$ (sequence in italics) of BRCA2 exon 18 (open box).

splicing alterations could be confirmed on patient blood RNA, except for $B R C A 1$ c.81-18C $>\mathrm{A}$, for which patient RNA was not available, and $B R C A 2$ c.68-7T $>$ A. An enhancement of exon 3 skipping, compared with controls, was observed for the latter variant in patient RNA, but this effect was not observed in the pCAS minigene assay. The reasons for this discrepancy are discussed below.

Variants not predicted to induce splice site changes, but producing an effect in minigene assays

Among the 43 type 2 predictions, we found five VUSs that induced splicing alterations in the minigene assay (Table 3 ). We have recently characterized in detail the effects of one of them, BRCA1 c. $5434 \mathrm{C}>\mathrm{G}^{13}$ The other variants shown in Table 3 also induced incomplete, but in some cases strong, skipping of the affected exon. These alterations were confirmed in patient RNA, except for BRCA1 c. $557 \mathrm{C}>\mathrm{A}$, for which a minor band corresponding to exon exclusion was found in the minigene assay, whereas patient RNA analysis showed only a slight enhancement of the isoforms with skipped exons 9 and 10. Notably, these five VUSs, with predictions classified type 2 and with consequences on RNA splicing, were all at internal exon positions. Conversely, none of the 15 VUSs with type 2 bioinformatics predictions but located at intronic positions (listed in Supplementary Table S1) showed an effect in functional splicing assays, nor in patient RNA, when available.

\section{DISCUSSION}

Evaluation of bioinformatics predictions of splicing alterations A major aim of this study was to evaluate bioinformatics predictions of splice site changes (changes of the scores of natural splice sites, creation of new splice sites or activation of cryptic splice sites) on a large collection of exonic and intronic VUSs that was generated during consecutive screenings in our molecular diagnostic laboratories. To avoid a bias in this evaluation, we have excluded changes at the nearly absolutely conserved GT/AG positions at the $5^{\prime}$ and the $3^{\prime}$ intron boundaries, as, with very few exceptions, they can be interpreted directly as having an effect on mRNA splicing. In a previous study, ${ }^{7}$ based on selected variants for which patient RNA was available, we have shown the accuracy of splicing minigene assays to assess the consequences of BRCA variants on RNA splicing. Here we evaluated the bioinformatics predictions primarily against results of minigene assays because these assays do not depend on the availability of patient RNA. At variance with previous publications, ${ }^{7,8}$ we studied all consecutive VUSs found in our molecular diagnostic activities without selection, except for VUS of the large exon 11 of BRCA1 and the large exon 11 of $B R C A 2$, which require special minigene constructs. ${ }^{14}$

We have used rather permissive criteria for the interpretation of the predictions of five algorithms (significant threshold of variation set at as low as $10 \%$ and concordance between two algorithms considered sufficient). By using these criteria, 10 of the 53 VUSs had type 1 predictions (ie, affected exon-intron junctions or generated new splice sites or induced the use of cryptic splice sites by lowering the strength of natural sites). Four of these VUSs indeed induced splicing changes in the minigene assay (Table 1), whereas six were associated with falsepositive predictions (Table 2). The observation of an important fraction of false-positive predictions underlines the need of patient RNA analyses and/or functional assays, even when multiple bioinformatics programs predict splicing alterations associated with important score variations.

The false-positive type 1 predictions may be explained in some cases (BRCA1 c.81-18C >A and BRCA2 c.517-20A > G, Table 2) by the criteria used for the interpretation of score differences, because in these cases most algorithms predicted either no change of splice site score or changes that were close to the threshold of $10 \%$ set in this study. However, the data shown in Table 2 globally indicate that falsepositive predictions of splicing defects may occur even when multiple algorithms predict variations of splice site strength. The specificity of bioinformatics predictions may be increased by requiring a higher percentage of score variation and possibly by taking into account not only the percentage of variation, but also the strength of the natural splice site. Houdayer et al ${ }^{9}$ used VUS of the RB1 gene as a model and proposed a threshold of $20 \%$ for the significant difference between variant and wild-type score. However, they also provided evidence that this threshold is too high to ensure optimal sensitivity. Different compromises between sensitivity and specificity may be chosen by varying the stringency of the interpretation of multiple algorithms. For example, for the variants of Table 1 that affect splice site strength and that induce splicing alterations, a defect is predicted even using stringent conditions, such as requiring a minimum of three algorithms with score difference of at least 20\% (see Supplementary Table S2). 
Table 3 Description of the five BRCA variants associated with type 2 predictions that induce splicing alterations in functional minigene assay

Detection of splicing defects

\begin{tabular}{|c|c|c|c|c|}
\hline $\begin{array}{l}\text { Gene, } \\
\text { location }\end{array}$ & $\begin{array}{l}\text { Variant nucleotide } \\
\text { (HGVS) codon }\end{array}$ & Minigene assay & $\begin{array}{l}\text { Analysis of patient } \\
\text { RNA }\end{array}$ & $\begin{array}{l}\text { Previous reports concerning pathogenicity } \\
\left(B / C / L_{\text {LVVD/literature }}^{\mathrm{a}} \text { and our family data }\right.\end{array}$ \\
\hline $\begin{array}{l}B R C A 1 \\
\text { exon } 9\end{array}$ & $\begin{array}{l}\text { c. } 557 C>A \\
\text { p.Ser186Tyr }\end{array}$ & $\begin{array}{l}\text { Incomplete effect: one transcript including exon } 9 \\
\text { and one transcript with aberrant skipping of } \\
\text { exon } 9 \text { (minor) }\end{array}$ & $\begin{array}{l}\text { Enhancement of isoform } \\
\text { with skipped exons } \\
9 \text { and } 10\end{array}$ & $\begin{array}{l}\text { BIC } 35 \text { times } \\
\text { Inconclusive (multifactorial LR model) } 26 \\
\text { Predicted neutral (multifactorial } \\
\text { LR model) }{ }^{15}\end{array}$ \\
\hline $\begin{array}{l}B R C A 1 \\
\text { exon } 23\end{array}$ & $\begin{array}{l}\text { c. } 5434 \mathrm{C}>\mathrm{G} \\
\text { p.Pro } 1812 \mathrm{Ala}\end{array}$ & $\begin{array}{l}\text { Incomplete effect: one transcript including exon } 23 \\
\text { and one transcript with aberrant skipping of exon } \\
23 \text { (major), as previously published }{ }^{13}\end{array}$ & Confirmed & $\begin{array}{l}\text { Inconclusive (thermostability assay; }{ }^{27} \\
\text { protein binding assay) }{ }^{27} \\
\text { Deleterious splicing defect (minigene assay; }{ }^{13} \\
\text { patient blood RNA) }{ }^{13}\end{array}$ \\
\hline $\begin{array}{l}B R C A 2, \\
\text { exon } 3\end{array}$ & $\begin{array}{l}\text { c. } 231 \mathrm{~T}>\mathrm{G} \\
\text { p.Thr77Thr }\end{array}$ & $\begin{array}{l}\text { Incomplete effect: one transcript including exon } 3 \\
\text { and one transcript with aberrant skipping of exon } 3 \text { (minor) }\end{array}$ & $\begin{array}{l}\text { Enhanced isoform } \\
\text { with skipped exon } 3\end{array}$ & $\begin{array}{l}\text { Reported once } 28 \\
\text { Our family data: } 2 B C \text { first degree }\left(60^{*}, 58\right)+1 B C \\
\text { second degree }(61)\end{array}$ \\
\hline $\begin{array}{l}B R C A 2, \\
\text { exon } 7\end{array}$ & $\begin{array}{l}\text { c. } 520 \mathrm{C}>\mathrm{T} \\
\text { p.Arg174Cys }\end{array}$ & $\begin{array}{l}\text { Incomplete effect: one transcript including exon } 7 \text { and } \\
\text { one transcript with aberrant skipping of exon } 7 \text { (major) }\end{array}$ & Confirmed & $\begin{array}{l}\text { Novel variant } \\
\text { Family } 1: 5 B C \text { first degree }\left(48^{*}, 54,65,44,60\right) \\
+1 B C \text { second degree }(50) \\
\text { Family } 2: 2 B C \text {, first degree }\left(37^{*}, 54\right)\end{array}$ \\
\hline $\begin{array}{l}B R C A 2, \\
\text { exon } 18\end{array}$ & $\begin{array}{l}\text { c. } 7992 \mathrm{~T}>\mathrm{A} \\
\text { p.lle2664lle }\end{array}$ & $\begin{array}{l}\text { Incomplete effect: one transcript including exon } 18 \\
\text { and one transcript with aberrant skipping of exon } 18 \text { (equal) }\end{array}$ & Confirmed & $\begin{array}{l}\text { Novel variant } \\
2 \mathrm{BC} \text { first degree (bilateral* } 36 \text { and } 40,43 \text { ) } \\
+1 \mathrm{BC} \text { third degree }(38)\end{array}$ \\
\hline
\end{tabular}

Abbreviations: BC, breast cancer; LR, likelihood ratio.

aLR.

${ }^{\mathrm{b}}$ Number of $\mathrm{BC}$ with age at diagnosis in parenthesis.

*Tested patients.

Using these stringent conditions, only two of the six variants listed in Table 2 would be false positives. However, an independent large set of variants, with experimentally observed effects or without effect on splicing, should be used for defining the best combination of programs and the interpretation criteria that may reduce false positives to a minimum, without affecting sensitivity.

Vreeswijk et $a l^{8}$ suggested that intronic VUS not predicted to alter splice sites by at least two of three informative algorithms should be considered most likely neutral without testing them on patient RNA. Although more subtle effects of intronic changes on gene expression cannot be ruled out, our data support their suggestion. In fact, we have examined 23 intronic VUS, all at positions distinct from the conserved dinucleotides at the exon boundaries (see the Supplementary Table S1) and found an effect on splicing only among variants with type 1 predictions (ie, the three intronic variants listed in Table 1). This observation suggests that, for stratifying variants before performing functional assays, a low priority may be given to intronic variants, for which no effect on splicing is predicted. Considering that exclusion from functional testing is an important medical issue, we suggest the use of the present definition of type 1 predictions (two algorithms predicting score difference of at least 10\%) until different criteria can be established on the basis of more extensive comparisons of bioinformatics predictions and experimental data.

On the other hand, we found that five of the nine VUSs that induced splicing alterations in the minigene assay were in group 2 of bioinformatics predictions and were all located at internal exonic positions (Table 3). These five VUSs would be missed, if one would use only predictions aimed at the detection of splice site changes (ie, type 1). These five variants are likely to affect exonic splicing regulatory elements, as we have already demonstrated for one of them (BRCA1 c.5434C>G). ${ }^{13}$ A detailed characterization of the effects on splicing of the other four exonic VUS listed in Table 3 is in progress.

\section{Contribution to the assessment of pathogenicity}

For each of the previously reported VUS listed in Table 1, the splicing alteration detected in minigene assays is in good agreement with previous predictions of pathogenicity, that were based on multifactorial likelihood ratio (LR) models. These models take into account multiple sources of data, including family data, tumor histopathology and co-occurrence with a deleterious mutation. ${ }^{15-17}$ For previously not reported variants, or when family data had not been discussed in the publication of particular variants, we list in Tables 1 and 3 (last columns) the relevant features of patients in the corresponding families.

BRCA1 c. $212+3 \mathrm{~A}>\mathrm{G}$, had been previously predicted to be a deleterious change, by using a multifactorial LR model. ${ }^{15}$ It was reported with no effect on splicing, ${ }^{18}$ but another study ${ }^{19}$ reported an effect in patient RNA. These discrepancies may reflect differences in RNA quality or stability of the relevant transcripts. Here we demonstrate that BRCA1 c. $212+3 \mathrm{~A}>\mathrm{G}$ is a deleterious splicing mutation, because it induces, in the monoallelic minigene assay, the complete loss of the mRNA form containing the full exon 5 sequence and its replacement by a mRNA coding for a truncated protein (Figure 1a).

BRCA1 c.5194-12G > A had been predicted to be deleterious using a multifactorial LR model. ${ }^{15}$ Here we show that it induces, in the minigene assay, the complete loss of the normal transcript and its replacement by an out-of-frame mRNA form (Figure 1b). After submission of this work, Whiley et al ${ }^{17}$ have reported the same major splicing defect observed in a lymphoblastoid cell line from a patient carrying this mutation.

For both intronic BRCA1 mutations discussed here, the monoallelic splicing minigene assay, combined with patient RNA data, contributes essential information to the assessment of pathogenicity by demonstrating a complete splicing defect. Although both assays are performed in cell types that are not directly relevant to breast or ovarian tumor formation (ie, in HeLa cells for the minigene assay and 
on RNA obtained from blood cells or from lymphoblastoid cell lines, for patient mRNA analyses) all splicing defects that fully abolish the use of the natural splice site and induce a frameshift should probably be considered pathogenic, such as the mutations of the conserved dinucleotides at intron boundaries.

BRCA2 c.7977-7C $>\mathrm{G}$ is a novel variant and induced a complete splicing alteration, because of the use of a new acceptor site and the inclusion of $6 \mathrm{nt}$ of intron 17 (Figure 1c). Classification of this novel variant awaits further evaluations of the functional consequences of the predicted inclusion of two amino acids into the BRCA2 protein and/or segregation data. Our family data are strongly suggestive of a $B R C A 2$ mutation in both families carrying this variant (last column of Table 1).

BRCA2 c.8168A > G (p.Asp2723Gly), located in the central position of exon 18, generated a new donor site that was partially used in the minigene assay and induced the production of a mRNA species lacking $164 \mathrm{nt}$ of exon 18 (Figure 1d). A frame shift is predicted for this mRNA. Our results are in keeping with recent minigene data ${ }^{20}$ and with patient data ${ }^{21}$ showing the same aberrant splicing in the RNA of a cell line obtained from a patient carrying this variant. On the basis of multifactorial likelihood analysis, this variant was classified as pathogenic (Table 1). ${ }^{15,16}$

Among the variants with type 1 predictions, but with no effect in the minigene assay, BRCA2 c.68-7T $>$ A (Table 2) deserves particular attention, because, in patient blood RNA, it enhanced the exclusion of exon 3, which is also observed at low levels in control samples. These observations are in keeping with two recent reports, ${ }^{8,20}$ but the relevance to cancer predisposition of this enhanced skipping of exon 3 , which is in frame, is still questionable, and thus BRCA2 c.68-7T $>\mathrm{A}$ should still be considered as a VUS. The discrepancy observed in this case between the results of our minigene assay and those of RT-PCR analyses on patient blood RNA reflects the nature of the minigene assay used, which targets single exons. When alternative splicing is observed in vivo, sequence variants that modify the relative levels of alternative transcripts can be detected reliably by testing the exon in its natural context, including at least the flanking exons, or by testing it as a single exon, but in a variety of minigenes and in different cell types. A similar explanation applies to the discrepancy observed in Table 3 for BRCA1 c.557C > A between the minigene assay and patient RNA analyses, because BRCA1 exons 9 and 10 are involved in the production of multiple alternative isoforms, ${ }^{23}$ but only exon 9 was tested in the minigene assay.

Several internal exonic variants induced moderate or even strong exon skipping in the minigene assay that were confirmed in patient RNA (Table 3). Strong exon skipping was observed, both in the minigene assay and in vivo, for BRCA1 c.5434C $>\mathrm{G}$, for BRCA2 c.520C $>\mathrm{T}$ and for BRCA2 c.7992T $>$ A. We have recently described the molecular basis of exon skipping induced by the BRCA1 c. $5434 \mathrm{C}>\mathrm{G}$ variant ${ }^{13}$ and detailed analyses of the effects on exonic regulatory elements of other variants shown in Table 3 are underway. For these variants and especially for $B R C A 2$ c.520C $>\mathrm{T}$, family histories are suggestive of the presence of a BRCA mutation, but at this stage of our study segregation analyses have not been possible.

This work shows that, by using current splicing prediction programs, one can select priorities for functional assays. We propose that VUS defined here as type 1 should be tested with priority, followed by testing all internal exonic variants using splicing reporter minigenes and/or RT-PCR on patient RNA. However, in this series of BRCA variants, this stratification of assays would have provided only a moderate gain in time and costs, because only 15 of the 53 VUSs would have been excluded from functional assays, that is, the 15 type 2 intronic VUSs (10 and 5 for $B R C A 1$ and $B R C A 2$, respectively, see Supplementary Table S1). Indeed, no splicing alteration was induced by these intronic variants, in keeping with the previous suggestion ${ }^{8}$ that intronic variants for which no effect on splicing is predicted, using multiple algorithms, could be excluded from further analyses. We support that suggestion, at least at the stage of the initial interpretation, in the molecular diagnostic setting, but one cannot exclude the possibility that intronic variants, distant from the exon boundaries, may induce more subtle splicing alterations. ${ }^{24}$

In conclusion, the current bioinformatics predictions of splice site strength variation or of creation/activation of new splice sites can be considered as a reliable and necessary tool for the stratification of patient RNA analyses and of functional splicing assays. They allow sensitive detection of VUS that induce splice site changes, but are rather unspecific, unless better rules are defined for the interpretation of score variations. On the other hand, exonic regulatory elements of the $B R C A$ genes should be identified experimentally and recently developed algorithms predicting alterations of these regulatory elements should be validated for use in the diagnostic setting.

\section{CONFLICT OF INTEREST}

The authors declare no conflict of interest.

\section{ACKNOWLEDGEMENTS}

The work of P Gaildrat and of A Killian was supported by the French Northwest Canceropole. JC Théry was the recipient of a fellowship from ARC (Association pour la Recherche sur le Cancer). Part of this work was supported by a grant from INCa (Institut National du Cancer).

1 Tutt A, Robson M, Garber JE et al: Oral poly(ADP-ribose) polymerase inhibitor olaparib in patients with BRCA1 or BRCA2 mutations and advanced breast cancer: a proof-ofconcept trial. Lancet 2010; 376: 235-244.

2 Walsh T, Lee MK, Casadei S et al: Detection of inherited mutations for breast and ovarian cancer using genomic capture and massively parallel sequencing. Proc Natl Acad Sci USA 2010; 107: 12629-12633.

3 Stalder L, Mühlemann O: The meaning of nonsense. Trends Cell Biol 2008; 18: 315-321.

4 Gaildrat P, Killian A, Martins A, Tournier I, Frébourg T, Tosi M: Use of splicing reporter minigene assay to evaluate the effect on splicing of unclassified genetic variants. Methods Mol Biol 2010; 653: 249-257.

5 Baralle D, Baralle M: Splicing in action: assessing disease causing sequence changes. J Med Genet 2005; 42: 737-748.

6 Tournier I, Vezain M, Martins A et al: A large fraction of unclassified variants of the mismatch repair genes MLH1 and MSH2 is associated with splicing defects. Hum Mutat 2008; 29: 1412-1424.

7 Bonnet C, Krieger S, Vezain M et al: Screening BRCA1 and BRCA2 unclassified variants for splicing mutations using reverse transcription PCR on patient RNA and an ex vivo assay based on a splicing reporter minigene. J Med Genet 2008; 45: 438-446.

8 Vreeswijk MP, Kraan JN, van der Klift HM et al: Intronic variants in BRCA1 and BRCA2 that affect RNA splicing can be reliably selected by splice-site prediction programs. Hum Mutat 2009; 30: 107-114.

9 Houdayer C, Dehainault C, Mattler C et al: Evaluation of in silico splice tools for decision-making in molecular diagnosis. Hum Mutat 2008; 29: 975-982.

10 Zampieri S, Buratti E, Dominissini S et al: Splicing mutations in glycogen-storage disease type II: evaluation of the full spectrum of mutations and their relation to patients' phenotypes. Eur J Hum Genet 2011; 19: 422-431.

11 Hogervorst FB, Nederlof PM, Gille JJ et al: Large genomic deletions and duplications in the BRCA1 gene identified by a novel quantitative method. Cancer Res 2003; 63: 1449-1453.

12 Casilli F, Tournier I, Sinilnikova OM et al: The contribution of germline rearrangements to the spectrum of BRCA2 mutations. J Med Genet 2006; 43: e49.

13 Gaildrat P, Krieger S, Théry JC et al: The BRCA1 c.5434C $\rightarrow$ G (p.Pro1812Ala) variant induces a deleterious exon 23 skipping by affecting exonic splicing regulatory elements. J Med Genet 2010; 47: 398-403.

14 Anczuków 0, Buisson M, Salles MJ et al: Unclassified variants identified in BRCA1 exon 11: consequences on splicing. Genes Chromosomes Cancer 2008; 47: 418-426.

15 Easton DF, Deffenbaugh AM, Pruss D et al: A systematic genetic assessment of 1433 sequence variants of unknown clinical significance in the BRCA1 and BRCA2 breast cancer-predisposition genes. Am J Hum Genet 2007; 81: 873-883. 
16 Goldgar DE, Easton DF, Byrnes GB et al: Genetic evidence and integration of various data sources for classifying uncertain variants into a single model. Hum Mutat 2008; 29: 1265-1272.

17 Whiley P, Guidugli L, Walker L et al: Splicing and multifactorial analysis of intronic BRCA1 and BRCA2 sequence variants identifies clinically significant splicing aberrations up to 12 nucleotides from the intron/exon boundary. Hum Mutat 2011; 32: 678-687.

18 Chen X, Truong TT, Weaver J et al: Intronic alterations in BRCA1 and BRCA2: effect on mRNA splicing fidelity and expression. Hum Mutat 2006; 27: 427-435.

19 Claes K, Vandesompele J, Poppe B et al: Pathological splice mutations outside the invariant AG/GT splice sites of BRCA1 exon 5 increase alternative transcript levels in the $5^{\prime}$ end of the BRCA1 gene. Oncogene 2002; 21: 4171-4175.

20 Sanz DJ, Acedo A, Infante M et al: A high proportion of DNA variants of BRCA1 and BRCA2 is associated with aberrant splicing in breast/ovarian cancer patients. Clin Cancer Res 2010; 16: 1957-1967.

21 Walker LC, Whiley PJ, Couch FJ et al: Detection of splicing aberrations caused by BRCA1 and BRCA2 sequence variants encoding missense substitutions: implications for prediction of pathogenicity. Hum Mutat 2010; 31: E1484-E1505.
22 Karchin R, Agarwal M, Sali A, Couch F, Beattie MS: Classifying variants of undetermined significance in BRCA2 with protein likelihood ratios. Cancer Inform 2008; 6: 203-216.

23 Dosil V Tosar A, Cañadas C et al: Alternative splicing and molecular characterization of splice site variants: BRCA1 c.591C > T as a case study. Clin Chem 2010; 56: 53-61.

24 Homolova K, Zavadakova P, Doktor TK, Schroeder LD, Kozich V, Andresen BS: The deep intronic c.903+469T>C mutation in the MTRR gene creates an SF2/ASF binding exonic splicing enhancer, which leads to pseudoexon activation and causes the cblE type of homocystinuria. Hum Mutat 2010; 31: 437-444.

25 Farrugia DJ, Agarwal MK, Pankratz VS et al: Functional assays for classification of BRCA2 variants of uncertain significance. Cancer Res 2008; 68: 3523-3531.

26 Tavtigian SV, Deffenbaugh AM, Yin L et al: Comprehensive statistical study of 452 BRCA1 missense substitutions with classification of eight recurrent substitutions as neutral. J Med Genet 2006; 43: 295-305.

27 Drikos I, Nounesis G, Vorgias CE: Characterization of cancer-linked BRCA1-BRCT missense variants and their interaction with phosphoprotein targets. Proteins 2009; 77: 464-476.

28 Hadjisavvas A, Charalambous E, Adamou A, Christodoulou CG, Kyriacou K: BRCA2 germline mutations in Cypriot patients with familial breast/ovarian cancer. Hum Mutat 2003; $21: 171$.

Supplementary Information accompanies the paper on European Journal of Human Genetics website (http://www.nature.com/ejhg) 